This is an accepted manuscript version for an article to be published in the journal Safety Science. Copyright to the final published article belongs to Elsevier.

(c) 2018. This manuscript version is made available under the CC-BY-NC-ND 4.0 license. http://creativecommons.org/licenses/by-nc-nd/4.0/

The final published version of this paper can be found via the following DOI:

https://doi.org/10.1016/j.ssci.2018.06.016

The final published version of this paper can be referenced as follows:

Thompson, O.F., Galea, E.R. and Hulse, L.M. (2018). A review of the literature on human behaviour in dwelling fires. Safety Science, 109, pp. 303-312. 


\title{
A review of the literature on human behaviour in dwelling fires
}

\begin{abstract}
Most fire-related injuries and fatalities in the UK, and other parts of the world, continue to occur during fires in the home - incidents where it is acknowledged that human factors play a contributing role. Yet the field of fire safety lacks an up-to-date review of the literature on human behaviour during fires in domestic spaces. Given there is now a growing body of work looking at human behaviour in dwelling fires, a review of the literature in this area is timely. Drawing from published studies, this paper sets out what is currently known about human behaviour in dwelling fires and highlights the differences that appear to exist between these spaces and what is known and accepted about human behaviour in public, commercial and industrial spaces. This paper then goes on to consider the nature of "fire risk", arguing that much of the work in this area continues to conflate, or fails to recognise the existence of, different types of risk profiles, instead considering fire risk as a single type of risk, based mainly on factors related to fatalities. However, research findings point towards fire risk as at least three separate forms: the risk of a fire occurring, the risk of fire injury and the risk of fire fatality. By drawing together the literature on human behaviour in dwelling fires this paper argues that those who survive dwelling fires cannot be considered as "near miss fatalities", but instead must be treated as a separate and distinct group.
\end{abstract}

Keywords: 'human behaviour in fire', 'dwelling fire', 'domestic fire', 'fire injury', 'fire fatality', 'fire risk', 'fire incidence', 'fire mortality'.

\section{Introduction}

The majority of literature on human behaviour in fires is focussed upon understanding human behaviour in fires occurring within public, commercial and industrial spaces - there is not a comparable body of literature focussing exclusively upon human behaviour in single family/occupant dwellings ${ }^{1,2,3,4}$. Although Wood, Bryan, and Canter et al., incorporated studies of behaviour during dwelling fires in their early research into the area in the 1970 s and early $1980 \mathrm{~s}^{5,6,7}$, since this period it is an environment that has been largely neglected in comparison with nondomestic settings. Moreover, the literature that does exist on human behaviour in domestic settings is focussed upon the identification of occupant risk factors related to fire fatalities within dwellings $8,9,10,11$, or studies of smoke alarm response and evacuation from high-rise

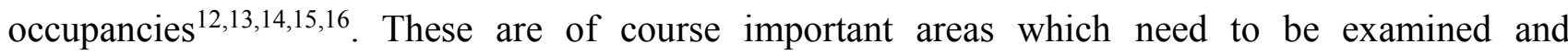
understood. However, it is the case that such research has not been accompanied by a commensurate 
level of focus upon the behaviour and motivations of those who survive fires in single occupancy domestic environments - either with or without injury ${ }^{7,17,18}$. This paper will establish what is currently known about human behaviour in dwelling fires and highlight the differences that appear to exist between these spaces and what is known and accepted about human behaviour in fires that occur in PCI (public, commercial and industrial) spaces - presenting the case for why behaviour in dwelling fires is deserving of a greater research focus. In addition this paper will consider the nature of "fire risk", arguing that dwelling fire risk cannot be considered as one single type of risk, instead it must be considered as three separate forms of risk: the risk of a fire occurring, the risk of fire injury and the risk of fire fatality. This paper asserts that despite efforts by some researchers to incorporate this distinction into work on dwelling fires, much of the effort in this area continues to conflate the three risk profiles, an approach which leads to an inaccurate and incomplete understanding of dwelling fires.

\section{Methods}

Internet searches of electronic databases (Google Scholar, Web of Science, EBSCOhost Research Databases) were undertaken using the keywords 'human behaviour in fire', 'dwelling fire', 'domestic fire', 'fire injury', 'fire fatality', 'fire risk', 'fire incidence', 'fire mortality'. In addition, hard copy conference proceedings from Human Behaviour in Fire, Interflam, Asiaflam, Flame Retardants, and the IAFSS symposia were used along with a CD-based compendium of human behaviour in fire papers ${ }^{19}$. Statistical and government sites in the UK and USA with online publications and reports were accessed along with several online university repositories (the University of Greenwich, the University of Huddersfield, the University of Ulster, and the University of Surrey) and the library catalogue of the UK Fire Service College. The focus of this paper is on accidental dwelling fires (ADFs). Here the distinction has been made between fires that have been deliberately started, perhaps as a result of arson, and fires which occur accidentally within a residential environment. It is noted that in the UK the general assessment made by the attending fire 
crews is sufficiently broad to always be able to make a determination concerning whether the fire was deliberate or accidental, thus the proportion of undetermined fires in the UK is negligible. Furthermore, while primarily concerned with ADFs occurring in the UK, where relevant, and in order to support any wider points being made, this paper also considers circumstances within the USA, Canada, Australia, New Zealand, Sweden and Japan. The reason for the inclusion of these particular countries is because of their status as leading sources of research into human behaviour in fire and papers published in English on this subject.

\section{Definition of terms}

The terms 'fatal casualty' (also referred to as fatality, fire fatality or fire-related death) and 'non-fatal casualty' (also referred to as injury) are often used in fire studies and while their definitions may appear self-explanatory, they can have different meanings to various audiences. The Home Office (the UK government department with responsibility for collecting and publishing fire statistics) attaches specific meanings to these terms. Fire fatalities are described as a death which is the direct or indirect result of injuries caused by the fire ${ }^{20}$. In this case a direct result would be a person being overcome and dying from exposure to the smoke and products of combustion, or through burns from the flames. An example of indirect result would be of a person jumping from a building to escape a fire and subsequently dying of the injuries sustained as a result of the fall while not injured by the fire itself, the actions the person undertook because there was a fire may be considered to have led to their death. The death could also occur weeks or months later as the timescale extends for 364 days after the date of the fire, thus giving a cut-off date of a year. With 'non-fatal casualties' the following four groups are defined by the Home Office for incident reporting standards: those given first aid at the scene of the fire; those taken to hospital with slight injuries; those taken to hospital with serious injuries; and those for whom there does not appear to be any obvious sign of injury or shock, but who are advised to attend hospital or see a doctor as a precaution $^{20}$. Thus UK fire statistics concerning non-fatal casualties cover a range of injuries, from 
very minor (not requiring hospitalisation) to very serious (requiring hospitalisation potentially for an extended period) without distinction. This paper also uses the abbreviation FRS when referring to the fire and rescue service (also known as fire brigades or fire departments).

\section{Fire, fatality and injury trends in the UK}

Perhaps the most striking aspect about the numbers of reported fires in the UK is the scale of the decline that has taken place since the millennium. In the space of 15 years, total recorded fires of all types have more than halved, falling from 445,000 in $2000 / 01$ to 200,000 in $2015 / 16$ (the peak of 572,000 fires occurred in 2003/04). Similarly, over the same period, ADFs witnessed a drop of approximately one third from 54,000 to just under $35,000^{20,21,22,23}$. A similar picture is evident for fire-related fatalities and injuries during the period 2000/01 to 2015/16 (Table 1). The number of fire fatalities have fallen by more than $30 \%$ and fatalities occurring in ADFs specifically have declined by $35 \%$. Although, it is worth noting that, as with overall fire fatalities, a few increases in ADF

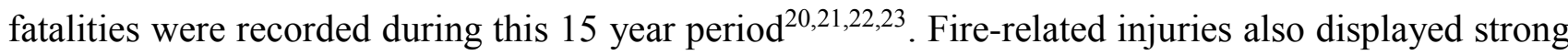
downward trends, declining by more than a third albeit, as with fatalities, with some slight increases during this period. This overall downward trend (and the years that saw sporadic increases) was similarly observed for injuries occurring in ADFs, the number of which fell by over a third $20,21,22,23$.

Table 1: Fatalities and injuries for all fires and ADFs, 2000 to 2015

\begin{tabular}{lllll}
\hline Year & All fire fatalities & ADF fatalities & All fire injuries & ADF injuries \\
\hline $2000 / 01$ & 554 & 363 & 16,542 & 11,263 \\
$2001 / 02$ & 583 & 404 & 16,907 & 11,348 \\
$2002 / 03$ & 522 & 341 & 15,055 & 10,200 \\
$2003 / 04$ & 576 & 359 & 15,228 & 10,226 \\
$2004 / 05$ & 483 & 322 & 13,672 & 9,476 \\
$2005 / 06$ & 470 & 286 & 13,578 & 9,323 \\
$2006 / 07$ & 430 & 249 & 13,088 & 8,902 \\
$2007 / 08$ & 458 & 291 & 12,669 & 8,714 \\
$2008 / 09$ & 404 & 268 & 11,533 & 7,987 \\
$2009 / 10$ & 416 & 275 & 10,652 & 7,244 \\
$2010 / 11$ & 388 & 268 & 11,134 & 7,776 \\
$2011 / 12$ & 380 & 244 & 11,300 & 7,729 \\
\hline
\end{tabular}




\begin{tabular}{lllll}
\hline $2012 / 13$ & 350 & 217 & 10,300 & 7,354 \\
$2013 / 14$ & 322 & 219 & 9,748 & 6,872 \\
$2014 / 15$ & 325 & 209 & 9,232 & 6,496 \\
$2015 / 16$ & 367 & 237 & 9,493 & 6,490 \\
\hline
\end{tabular}

Source: DCLG, 2015²0; Home Office, 2016 ${ }^{21}$; Scottish Fire and Rescue Service, 2016²2; Welsh Government, $2016^{23}$. NB. From 2008, data collected changed from the UK to Great Britain.

However, it has not always been a story of decline. The number of fires in 2015 is around double that experienced in 1950 - a trend that may appear to correlate with the growth in the number of UK dwellings since 1950 (there are now twice as many dwellings - approximately 28 million in $2014^{24}$ - while the population is a third greater -64 million in $2013^{25,26}-$ than in 1950). As Figure 1 shows, however, there was actually a period of growth that was then halted and reversed. The number of dwelling fires underwent a steady increase since 1950, slowing somewhat through the 1980s and 1990s before beginning to decline at the start of the millennium. The point to note here is that - accepting that the figures represent an amalgam of both deliberate and accidental dwelling fires, the distinction only being made from year 2000 onwards - the fall in reported dwelling fires means that in the space of 15 years the current figure has fallen to approximately the same level as in the late 1960s. 


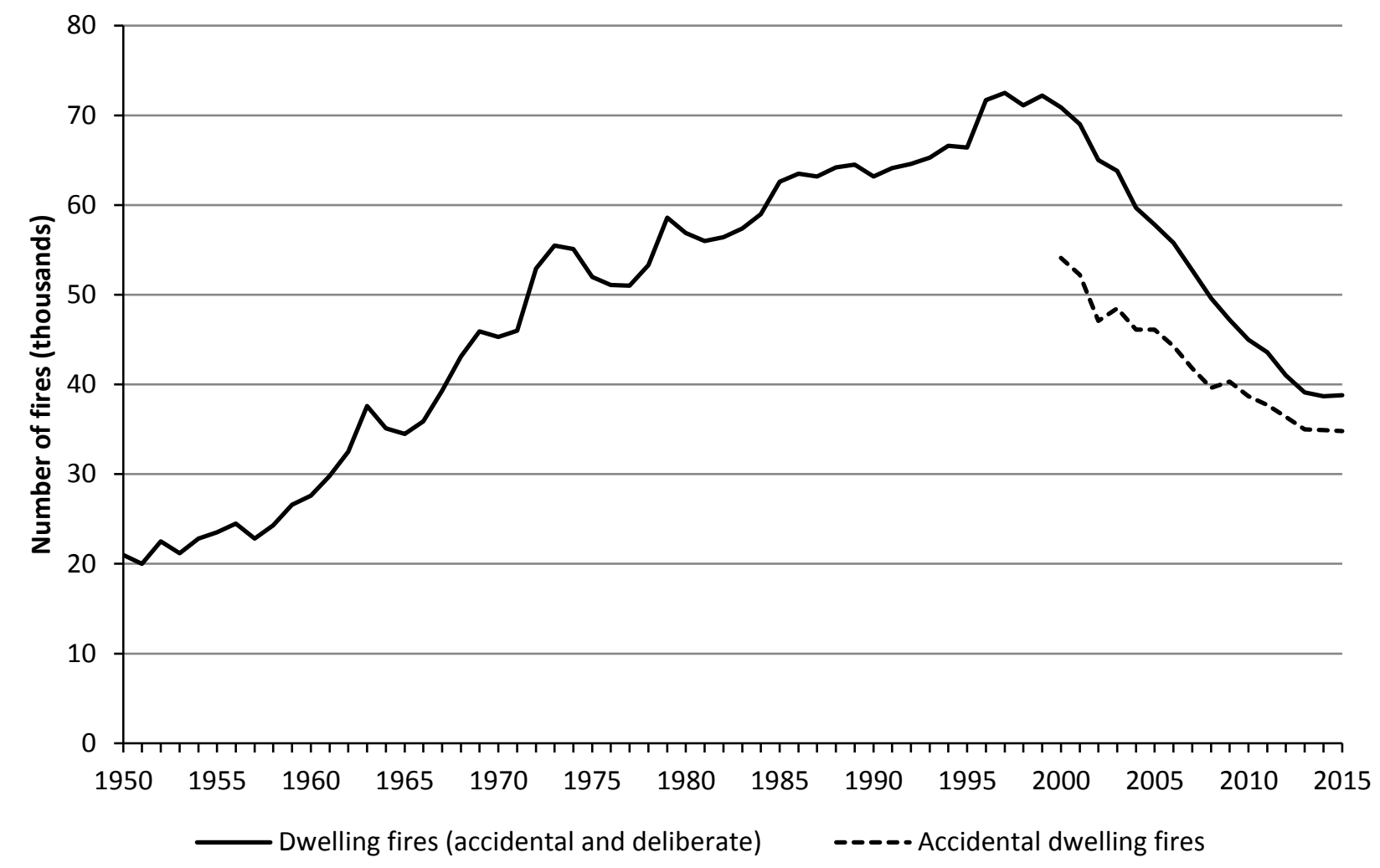

Figure 1: UK dwelling fires, 1950 to 2015 (ADFs recorded from 2000). Source: DCLG, 201027; DCLG, 2015 ${ }^{20}$; Home Office, 2016 ${ }^{21}$; Scottish Fire and Rescue Service, 2016 ${ }^{22}$; Welsh Government, 2016 ${ }^{23}$. NB. From 2008, data collected changed from the UK to Great Britain.

To make international comparison possible, Figure 2 presents UK dwelling fires per 100,000 people for the same period (1950 to 2015). It is interesting to note that since the millennium the number of fires per 100,000 people has halved, despite a ten percent increase in the population over the same period. 


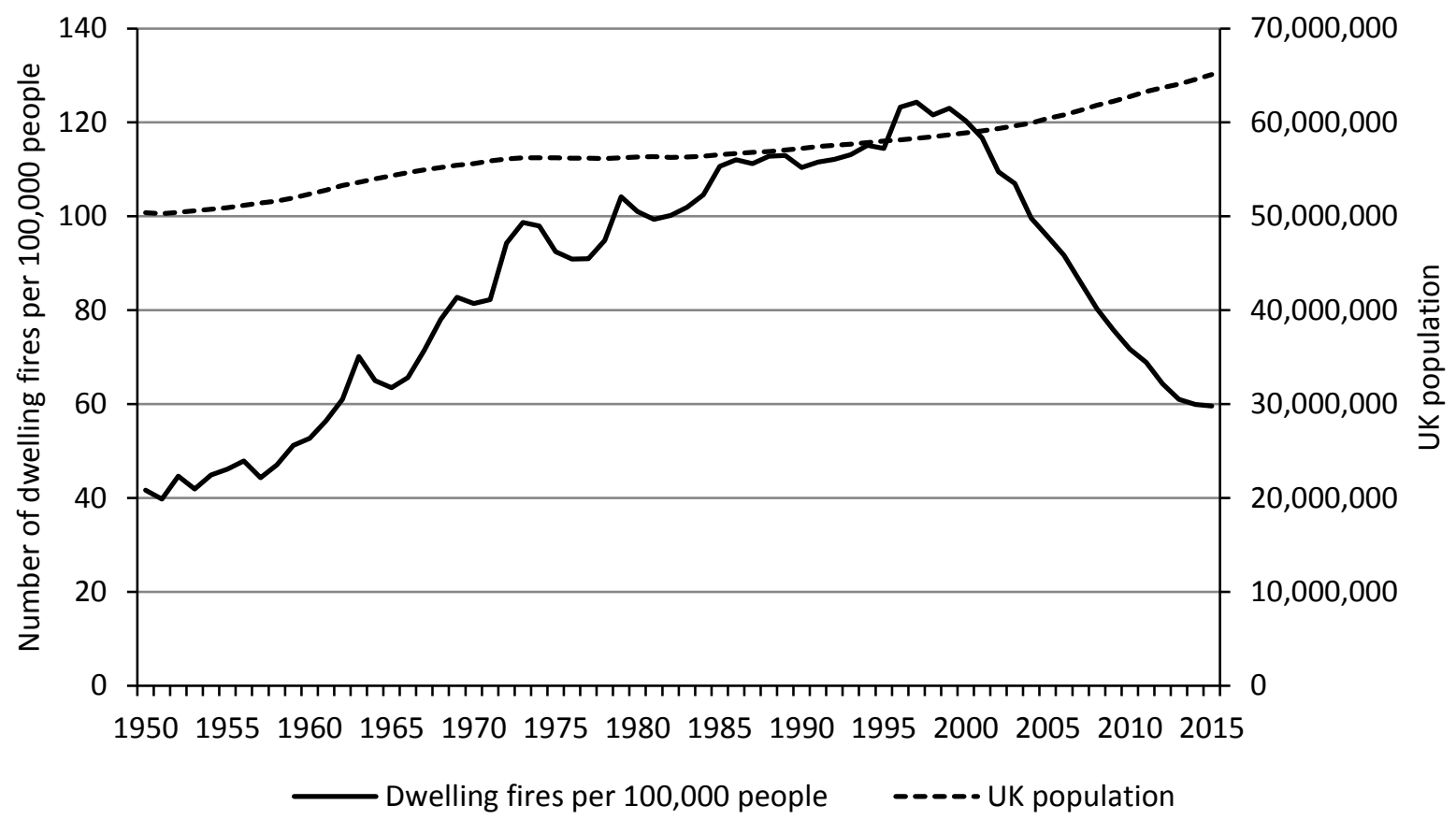

Figure 2: UK dwelling fires per 100,000 people and the UK population, 1950 to 2015. Source: DCLG, 201027; DCLG, 2015 ${ }^{20}$; Home Office, 2016 ${ }^{21}$; Scottish Fire and Rescue Service, 2016 ${ }^{22}$; Welsh Government, 2016 ${ }^{23}$; ONS, $2018^{26}$.

An overview of dwelling fire fatalities since 1960 shows that their downward trend was first observable at the end of the 1970s, with the number of fatalities declining by $47 \%$ in the period 1979 to 2000 and then by a further $38 \%$ in the period since the millennium ${ }^{20,21,22,23}$ (Figure 3 ). It may be reasonable to assume that these figures will be subject to historical limitations imposed by the varied data collection and reporting standards of different FRSs - and in some countries that may be the case. However, the UK has employed a standardised and nation-wide method of fire incident reporting for almost 70 years. The current electronic reporting system, known as the Incident Recording System (IRS) was introduced in 2009 and replaced the hard copy Fire Damage Report (FDR1), which was itself a replacement for the earlier K433 fire report form which had been in existence since the late 1940s. In varying formats all three methods of incident data collection sought, where appropriate, to obtain detailed information about the incident: the origin, cause, location, size and type of fire, building type and construction methods, and any fatalities or injuries. This means that, through information collected by the FRS on incidents attended, the UK has a rich 
data set on fires stretching back over a number of decades.

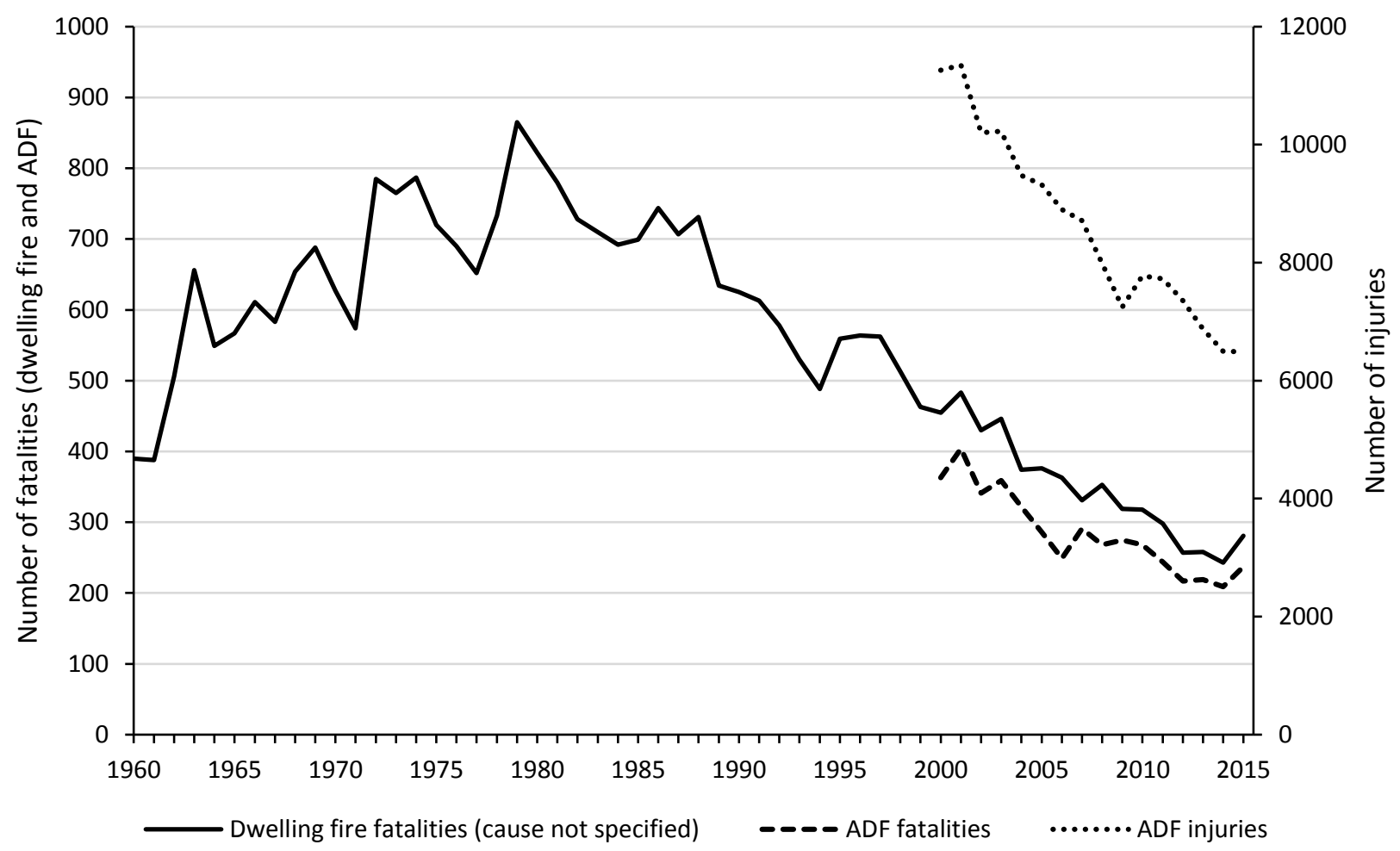

Figure 3: Fatalities and injuries in dwelling fires, 1960 to 2015. Source: DCLG, 201027; DCLG, 2015 ${ }^{20}$; Home Office, 2016 $6^{21}$; Scottish Fire and Rescue Service, 2016 ${ }^{22}$; Welsh Government, 2016 ${ }^{23}$. NB. From 2008, data collected changed from the UK to Great Britain.

Again, in order to allow international comparison to be made, dwelling fire fatalities are presented per 100,000 people (see Figure 4). It is interesting to note that when normalised per 100,00 people, both the number of dwelling fires and the number of dwelling fire fatalities (Figures 2 and 4 respectively) declined from their respective peaks by a larger proportion compared to the counts (Figures 1 and 3). By 2015, the number of dwelling fires had declined by $46 \%(72,500$ to 38,800$)$ from their peak in 1997 (Figure 1). However, when measured per 100,000 people, the decline from the peak year in 1997 was $52 \%$ (124.3 to 59.6 people per 100,000).

With dwelling fire fatalities, a decline of $68 \%$ has occurred since the peak in 1979 , falling from 865 to 281 in 2015 (Figure 3). By comparison, over the same period, the number of dwelling fire fatalities fell from 1.54 to 0.43 per 100,000 people - a fall of $72 \%$. The greater decline in the 
normalised number of dwelling fires and fire fatalities is all the more impressive as the overall UK population has increased over this period.

However, as shown in Figure 5, these declines in the incidence of dwelling fires and associated fatalities have not been accompanied by a decline in the likelihood of dying or being injured should a dwelling fire occur.

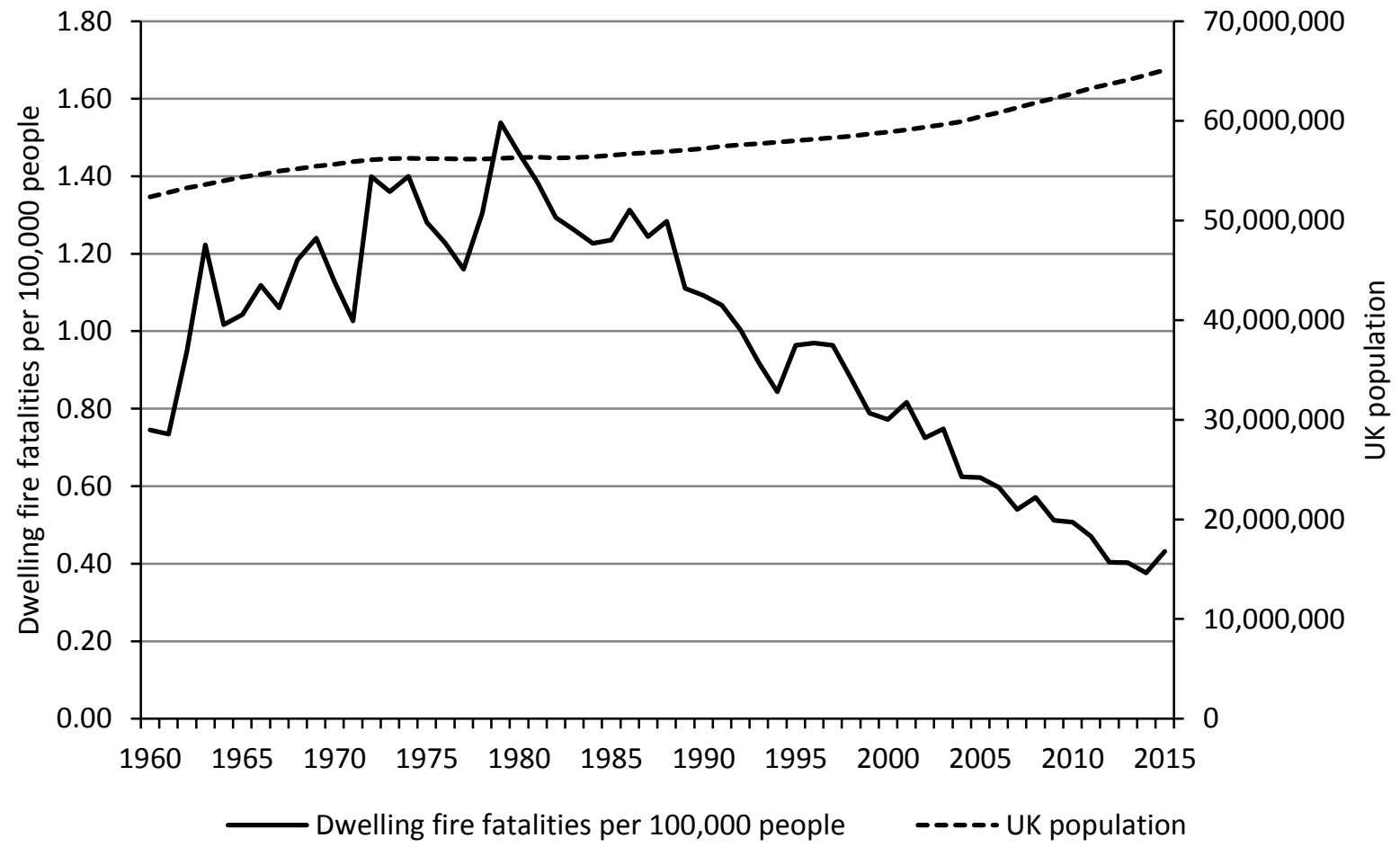

Figure 4: UK dwelling fire fatalities per 100,000 people and the UK population, 1960 to 2015. Source: DCLG, 201027; DCLG, 201520; Home Office, 2016 21 ; Scottish Fire and Rescue Service, 2016 22; Welsh Government, 2016 23 ; ONS, $2018^{26}$.

\section{The importance of understanding human behaviour in ADFs}

Despite the large declines that have been presented, upon closer examination of the data for dwelling fires, a slightly more complicated picture emerges. For although ADFs account for between only $8 \%$ and $20 \%$ of all fires by type they are the cause of between $58 \%$ and $70 \%$ of all fire-related injuries and fatalities. Furthermore, since the millennium, despite the decline in the number of fires, fatalities and injuries, this proportion has remained broadly consistent ${ }^{20,21,22,23}$ (Figure 5). In fact, 
since 1999 the fire fatality rate in dwelling fires has reached something of a plateau, fluctuating between 0.63 and 0.72 fatalities per 100 fires $^{20,21,22,23,27}$. The same is also true with the risk of being injured in a dwelling fire, as since the millennium the injury rate has also remained fairly constant at between 17.6 and 20.6 non-fatal casualties per 100 dwelling fires, with a median of $19.3^{20,21,22,23}$.

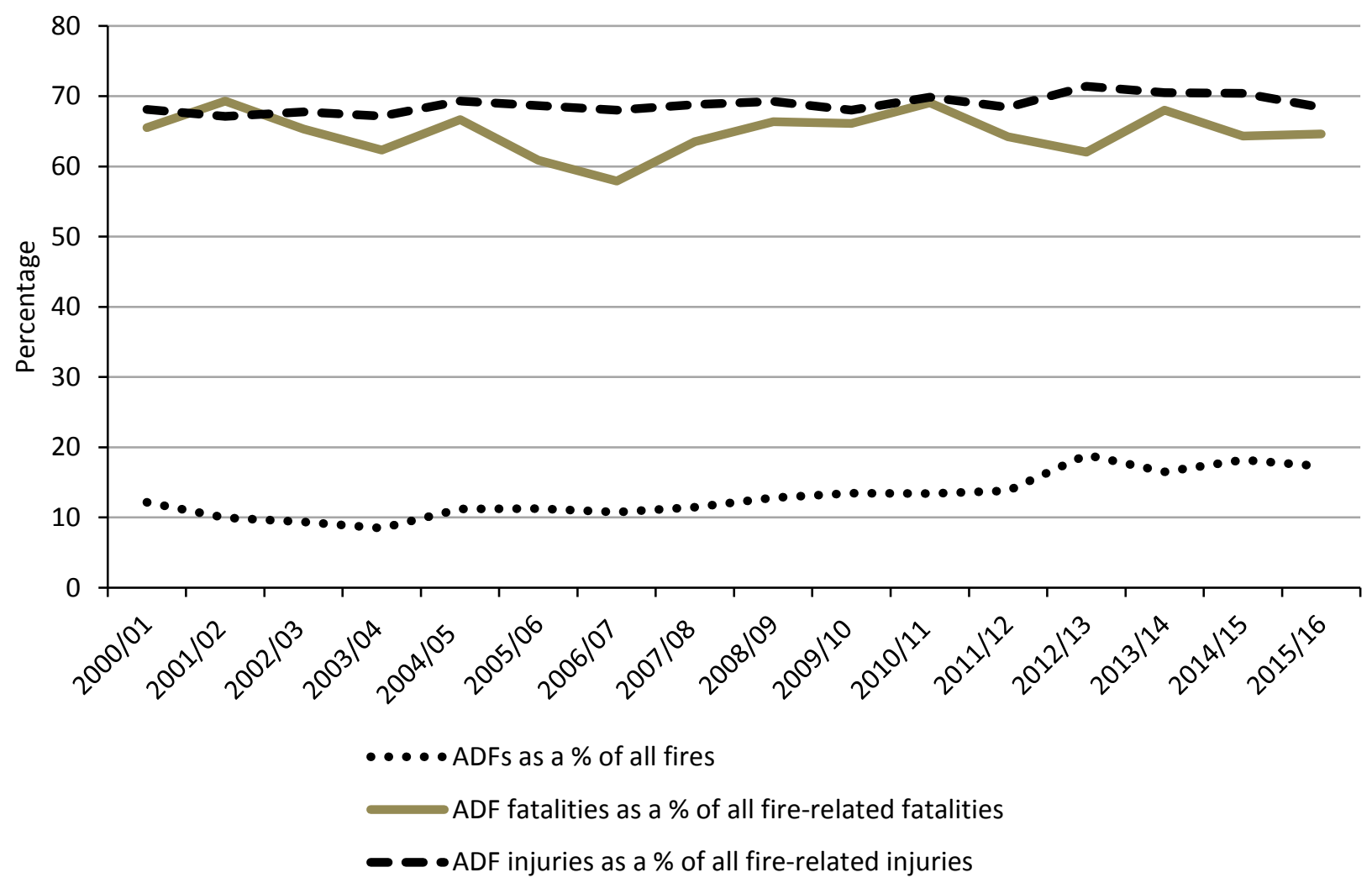

Figure 5: ADFs as a proportion of all fires, fire-related fatalities and fire-related injuries, 2000 to 2015. Source: DCLG, 2015²0; Home Office, 2016 ${ }^{21}$; Scottish Fire and Rescue Service, 2016 22; Welsh Government, $2016^{23}$. NB. From 2008, data collected changed from the UK to Great Britain.

As a result, it can be seen that the reductions in overall numbers of fires, fatalities and injuries conceal an important point, which is that while the risk of having an ADF has reduced, the risk of dying or being injured in an ADF has not. Consequently, as accidental fires in the home continue to be the leading cause of all fire-related fatalities and injuries they are an area about which a greater understanding needs to be developed. In addition, there is a significant socio-economic cost from fire, particularly when considering that in 2008 (the most recent year for which data are currently 
available) the cost of fire in England (accidental and deliberate fires of all types) was estimated at $£ 8.3$ billion, which includes the cost of damage to property, lost business and the cost of injuries and fatalities, through treatment costs and lost economic output arising from fire-related injuries - to say nothing of the stress, emotional and mental trauma caused to people by fire ${ }^{28}$. Indeed, the economic impact of such injuries and fatalities is considerable as, using this model, the estimated cost of fatal and non-fatal casualties was $£ 1.4$ billion for England alone ${ }^{28}$.

British statistics reveal that the leading source of ignition in cases of ADF fatalities is smokers' materials (defined as cigarettes, cigars and pipes) which result in over a third of all fatalities (37\%). This is followed by cooking appliances at $14 \%$ and space heating appliances at $9 \%$. The three main sources of ignition in cases of ADF injuries are cooking appliances, which account for more than half of all fire-related injuries (53\%), other electrical appliances and smokers' materials, the latter two each accounting for $10 \%$ of injuries ${ }^{20}$. In the majority of cases these sources of ignition do not occur independently from the actions of people ${ }^{*}$; human factors are the leading cause of fire ${ }^{20}$.

For all of the data collected by FRSs, data on the actions occupants undertake are not collected and recorded in detail. Where occupant behaviour is considered it will be where it is seen as relevant to the cause of the fire, as opposed to attempting to provide a narrative account of a person's actions throughout the duration of the fire - a focus best described as looking at how the fire affected the occupant, rather than the reverse. Furthermore, in the rare cases where that has been examined and compared, evidence supports the view that experts' (i.e. operational firefighters) predictions of human behaviour in fire do not match what has been observed on actual behaviours undertaken by survivors of dwelling fires ${ }^{29,30}$. Consequently a greater understanding of the behaviours, motivations and cognitions of those experiencing a dwelling fire will assist FRSs in the

\footnotetext{
"Within the British fire statistics The 'cause of fire' is defined as: "The defect, act or omission leading to ignition of the fire" (DCLG, 201520, p55), while 'source of ignition' describes: "The source of the flame, spark or heat that started the fire" (DCLG, 201520, p54). These two categories are used to offer greater detail in fire reporting by attempting to distinguish between the antecedent actions or circumstances that led to the fire and the physical cause of the ignition itself.
} 
UK and overseas with incident planning for operational response to and management of dwelling fires, firefighter and incident command training courses, emergency call handling procedures, and fire prevention and community safety initiatives.

\section{The incompatibility of applying existing knowledge to fires in dwellings}

Based upon what has been presented above, it would be reasonable to reflect on whether the considerable amount that is known about human behaviour in fire in PCI spaces could be applied to the domestic setting. However, as this paper will demonstrate, the greatly different sets of circumstances and associated influences acting upon occupants during a dwelling fire mean that it would be unwise and over-simplistic to automatically transfer accepted behavioural responses and actions during fires which occur in PCI spaces to domestic spaces.

It was not until the early 1970s and the work carried out by Wood and the UK's Fire Research Station that the first formal study dedicated to investigating the actions (as distinct from movement) people undertake when encountering a fire in a building, and using data derived from numerous real fires in various building types, was undertaken ${ }^{5}$. Following the work undertaken by Wood, a study was commissioned by the U.S. Department of Commerce's National Bureau of Standards and led by John Bryan ${ }^{6}$. Both studies utilised questionnaire surveys as the main method of data collection with dwellings comprising the single greatest building type. Wood's study contained data from 952 incidents and 2193 participants, for Bryan's study the corresponding figures were with 335 incidents and 584 participants ${ }^{5,6}$. Importantly, although not specifically differentiating between building types within the analysis and subsequent reporting, both studies identified behaviours that are now recognised as key aspects of human behaviour during a fire; in general terms both studies found evidence of people attempting to tackle fires; movement through smoke, re-entry behaviour, and clear differences between males and females in behaviour and frequency of certain behaviours (males were more likely to exhibit fire-fighting behaviours whereas females were more likely to alert others and exit the property $)^{5,6}$. Also in this first study of behaviour in fire was Wood's demonstration 
of the theory that people tend to behave rationally during fires, an emergent idea that was gaining increased interest following earlier work challenging the idea of "panic" 31 . Even at this early stage in the study of the area, Wood argued that, when looking at behaviour in real fires, people generally behave in a rational and logical manner, given the information available to them at the time ${ }^{5}$.

Among the limited literature in this area, one of the few studies to undertake a specific discussion of the differences between fires in the home, hospitals, multiple occupancies and public buildings was that by Canter et al. ${ }^{7,32}$. In this work it is argued that in fires in the home, people frequently find early cues ambiguous and frequently ignore or misinterpret these initial cues ${ }^{32}$. The authors state that this ambiguity, ignoring cues and general absence of an immediate response is characteristic of the informal and unstructured situation found in a single occupancy dwelling compared to a PCI space. However, it is important to note that the point made by Canter et al. about the delayed initial response to cues is contradicted by later work from other researchers, which instead argues that the initial response to fire cues within the domestic environment is actually quicker than for other building types - although often without awareness among the responding occupants that those cues are representative of a fire $e^{4,33,34,36,37,38}$. Although the amount of work conducted in this area is limited, Proulx states that the typically "lethargic" response to fire alarms, voice communication, and the initial cues of a fire is different in low-rise residential buildings, as occupants will rapidly respond to and investigate unusual smells, noises, or other changes to that immediate environment ${ }^{34}$. This difference is explained as being the result of the feelings of responsibility for the clearly defined physical space represented by this type of building $\mathrm{g}^{33,34}$. Proulx goes on to identify the key factors that exert an influence upon response time within what she calls the pre-movement phase, of which building type is identified as playing an important role ${ }^{35}$. In contrast to the delay so frequently observed for other types of building, cues generated from fires occurring in dwellings (such as the smell of burning or the sound of a smoke alarm) are sufficient to precipitate a swift response $\mathrm{s}^{33,34,35}$. 
More recently, this was highlighted in a qualitative study of behaviour during dwelling fires, in which it was observed that participants acted quickly in response to a variety of cues ${ }^{4}$. In line with Proulx, it is believed that the speed of the response to these initial cues - irrespective of whether those present knew at that time there was a fire or not - is a consequence of the nature of the sociophysical environment, in which people are in a clearly bounded and defined physical and social space that represents their most intimate environment. As such this sense of ownership, responsibility and control over this space (shared or otherwise), and likely presence within this space of loved ones, leads people to act in a way that is less bounded by the constraints (such as a fear of embarrassment, a desire to conform, a lack of direct responsibility towards that space) that may exert an influence upon behaviour and cue response within PCI spaces and buildings $s^{7,18,33,34,35}$.

With regard to terminology, Proulx refers to the 'pre-movement phase ${ }^{35}$, which is the first part of a two-phase description of the occupant's fire response (the other being the phase where the occupant commences evacuation). However this approach tends to over-simplify the process as it suggests that movement only occurs as part of an evacuation, which is not the case as people move around the building, potentially undertaking many tasks before they begin to actively start to evacuate (if indeed evacuation occurs at all). Consequently a more compelling way of describing the process is to define the two phases as a Response Phase and an Evacuation Movement Phase. During the Response Phase the occupant responds to incident cues which may involve them undertaking a range of activities before finally starting purposeful evacuation movement towards an exit or place of relative safety ${ }^{36,38,39}$. Furthermore, the duration of the Response Phase is called the response time rather than the pre-movement time.

\section{Closed versus open building systems}

It would appear that the key factor that underpins the differences between behaviour in fires across environments and spaces is that buildings may be considered as either "closed" or "open" systems ${ }^{40}$. Closed-building systems (which describe PCI spaces) are those where activities are 
formalised and managed and in which processes are controlled. Such closed-building systems manifest themselves through the presence of building codes (both prescriptive and performancebased), and identifiable, often hierarchical management structures (relating to both the building and those using it $)^{40,41}$. By contrast dwellings may be considered as open-building systems; places where there is not a formalised management structure relating to the building and the manner in which it is used, including the absence of any roles prescribed by fire safety codes and regulations ${ }^{40,41,42}$. This means that people's responses in the single occupancy domestic environment will not be subject to the social influences exerted upon them by the requirements and structures inherent within closedbuilding systems $\mathrm{s}^{40,43}$. Moreover, where the fire and smoke conditions allow, more people are able to exercise a greater degree of choice in their actions in relation to the fire. In addition, Proulx and Fahy have stated that within domestic spaces a greater number of occupants are more likely to have a responsibility for others such as their loved ones, principally children or the elderly ${ }^{44}$. Consequently, from this seemingly straightforward distinction arise a number of important differences related to the two kinds of system which, when considering fires in dwellings, may be summarised as follows:

- A greater (primarily familial) attachment to the building, people and items within it it $^{78,33,34}$.

- Fewer incidences of task attachment and faster response to alarms and ambiguous cues $2,4,33,34,35,36,37,45,46$.

- Absence of staff or fire wardens to organise and direct behaviour according to formalised procedures and operating within recognised hierarchies $7,32,40,41,47,48$.

- A greater propensity to attempt to tackle and or mitigate a fire. ${ }^{5,6,32,40,41,43,49,50}$.

- Greater incidence of re-entry ${ }^{5,6,51,52}$.

- Greater familiarity with the environment in what is generally a smaller space, resulting in wayfinding being less of an issue than in PCI spaces ${ }^{53,54}$. 
- Different occupancy types and characteristics; for example, greater numbers of children and the elderly ${ }^{5,6,49}$.

- The presence and effects of feelings of guilt and or responsibility for causing the fire and the resultant desire to deal with this before deciding whether to make an emergency call or not ${ }^{4}$. In the UK, USA, Canada and Australia it is estimated that between $60 \%$ and $80 \%$ of dwelling fires are not reported to the FRS $20,50,53,55$.

\section{High-rise dwellings}

Considering high-rise occupancies it may be argued that they display some elements of both systems as they present a combination of open building systems (the private spaces represented by the individual flats or apartments) and closed systems (the communal areas, stairwells, lifts, and building entrances and exits). In this regard such occupancies may be considered to present something of their own category, where, although less formal than a PCI space, a form of overall building organisation nonetheless exists ${ }^{32}$. Canter et al. argue that the pattern of behaviour in highrise occupancies is actually more complex than for single occupancy dwellings, something that is a function of both the number of potential information sources and appropriate actions ${ }^{7}$. The same researchers also identify that there are often fewer attempts to fight a fire compared to single occupancy dwellings ${ }^{7,32}$. Other differences within such environments include Bryan's observed phenomenon of "convergence clusters"49. Identified from his studies of hotel fires, this describes behaviour where individuals gather, or cluster, together in rooms as a form of communal refuge, and, importantly, was noted in the Lakanal House high-rise residential fire that occurred in London, $\mathrm{UK}^{3,16,49}$. Proulx also argued that by their very nature, PCI spaces, including high-rise occupancies, need to take into account specific building characteristics, not just occupancy classification ${ }^{33,34,35}$. In addition to this the management of a building is an important characteristic. Both of these are not features present in single occupancy dwellings ${ }^{33,34,40}$. Moreover, during a fire in a high-rise occupancy, the initial response of those alerted by an alarm, but who have not received direct 
confirmation of the fire, is likely to be characterised by the ambiguity and delayed response that is commonly seen in PCI spaces ${ }^{33,45}$. Similar characteristics were also observed in an earlier study conducted by Brennan on a fire in an 18-storey block of flats in Australia, which found frequent delay in response to alarms and recorded times from first being alerted to beginning evacuation that ranged from one minute to over twenty minutes ${ }^{56}$.

\section{The study of fire fatalities in dwellings and dwelling fire fatality risk factors}

The literature that considers risk factors related to fatal dwelling fires predominantly derives from work undertaken in the UK, USA, Japan, Australia and New Zealand and a number of consistent themes emerge. As mentioned earlier, fires started by discarded or improperly extinguished cigarettes are identified as the leading ignition source of fires that result in fatal outcomes; a finding observed not just in the UK but also in these other geographical regions $^{9,10,57,58,59}$. Those who are identified as being over-represented in dwelling fire fatalities are: the young and the old (those aged under five and over 65 years respectively); those who have a physical or cognitive impairment; those who undertake or engage in behaviour which is likely to limit their ability to recognise and or respond to a fire (generally speaking the consumption of alcohol or recreational drugs); those who live in social isolation; smokers; and those living in areas of deprivation ${ }^{8,10,54,59,60,61}$. However, it is important to note that this describes a mixture of interrelated causal and non-causal factors. For example, being a smoker does not on its own make a person more likely to die in a fire. However, among smokers there may be a higher incidence of individuals who have a characteristic or engage in behaviour that limits their ability to recognise and respond to a fire the home. Examples of which may include having a physical impairment, or alcohol consumption to a point where the ability to recognise and respond to fire cues becomes nullified ${ }^{8,57}$. There may also be a higher risk of a linked secondary factor: an increased risk that the children of smokers will have a greater likelihood of obtaining lighters and matches in the house. It has been demonstrated in studies looking at causes of fire fatalities and the presence of factors that may impair 
physical and cognitive response that there has often been an association with fires where the source of ignition is smoking materials and evidence of intoxication through alcohol ${ }^{59}$.

\subsection{Deprivation}

The issue of deprivation is important and deserves consideration, but not because it is a causal factor in and of itself, indeed to assume so would be a mistake. Rather it is the case that in deprived areas one tends to find a greater agglomeration of factors that increase the risk of fire fatality and with this an over representation of groups and individuals who display those factors $57,59,61,62,63$

\subsection{Age of housing}

In the USA, with its larger number of wooden-built properties and much younger housing stock than the UK, the age of housing has been identified as being directly related to the fire safety of the property and likelihood of a fire starting ${ }^{10,64}$. However, within the UK the age of housing alone is not identified as an issue, rather it is the quality of housing - in the UK there is no relationship between the age of a property and its quality. It has been argued that the quality of housing is closely related to deprivation and the associated risk factors surrounding the incidence of dwelling fires. Other factors associated with poor quality housing are overcrowding (increasing the risk of injury should a fire start), and poor maintenance of communal areas, escape routes, and smoke alarms ${ }^{61}$.

\subsection{Age of occupants}

In considering age, among the elderly age-related health conditions may restrict the ability to identify fire-related risks within the home and, in the event of a fire breaking out, impair the ability to identify the fire cues and limit the ability to move away from the fire to a place of safety ${ }^{10,65}$. Large numbers of the elderly also live alone and experience a greater degree of social isolation ${ }^{60,66}$, consequently, prior to a fire they may have not been in receipt of fire safety advice and during a fire there may not be others in the property to aid evacuation and offer assistance ${ }^{54,61}$. Furthermore, following a fire there is an age-related reduction in the ability to overcome and recover from both 
burn injuries and the injuries sustained from exposure to the products of combustion ${ }^{67,68,69}$. For young children, in addition to difficulties in being woken by smoke alarms, once a fire starts they lack the experience to recognise the risk posed by the fire and smoke and associated cues and also the ability to respond effectively, including the capacity to evacuate unaided ${ }^{10,64,67,70,71,72}$.

\subsection{Cultural heritage and native language ability}

Native language refers here to the official language of the country and the language spoken by the vast majority of the inhabitants. For countries such as the UK, Australia and USA this would be English. In their study on the 16 fatal fires that occurred in 2001 in New South Wales, Australia, Lewis and Lear identified those from non-English speaking backgrounds as being at increased risk ${ }^{57}$. However, this was because those who originated from non-English speaking backgrounds were overly represented in other risk groups such as low socio-economic status and living in public sector housing. It also raises an interesting question about whether a poor standard of English impaired their ability to access and interact with government and local authority services - including sources of home fire safety advice. Although in the USA it has been argued that non-white ethnic groups are at higher risk of experiencing an ADF, within the UK there appears to be no clear link between ethnicity and fire risk ${ }^{73,74}$. Moreover, it is important to clarify that among studies undertaken in the USA, it is the over representation of certain non-white ethnic groups in deprived areas, deprivation and single parent households that are associated with more fires, rather than their ethnicity itself. However, it is important to understand whether an increased fire risk exists among those who have recently entered the UK from countries which do not have a comparable standard of fire safety culture and risk awareness, as recent work from Sweden suggests that this may be the case there ${ }^{75}$.

\section{The identification of different risk profiles: fire occurrence, fire injury, fire fatality}

Despite the work on identifying the occupant risk factors related to fire fatalities, and the ability through fire service data and fire investigation reports to identify the most likely cause of a fire, an important point that has received only sporadic attention is the understanding of the 
distinction between being at risk of a fire occurring and being at risk of injury or death during a fire. Among the studies looking at fire fatality-related risk factors there has been a tendency not to differentiate between risk of a fire occurring, risk of injury, and risk of fire fatality, but simply amalgamate the three; an approach that has led to two questionable assumptions: firstly, that those groups who have more fires are the same as those groups who tend to die in fires; secondly, what these authors call the "conveyor belt theory", namely the assumption that once a fire starts those present move along a pre-determined path of increasing injury severity that, without the intervention of others, ends in death, thereby confining injuries to the status of near miss fatalities ${ }^{4,51,52,59,76,77,78}$.

A paper by Breslin et al. regarding changing the kinds of behaviours that lead to ADFs identified four main behaviours associated with dwelling fires: smoking, alcohol consumption, cooking practices and use of electrical appliances ${ }^{77}$. Unfortunately, in addition to failing to identify a distinction between risk of fire occurrence and fire fatality, this paper contains a number of questionable statements. Although the authors correctly state that cooking appliances are a common source of ignition, this paper is factually incorrect in its assertion that chip pans were a common cause of non-fatal fire incidents, as data from the Great Britain fire statistics show that for the period 2013-14, chip pans were the cause of just $6.7 \%$ of all ADFs and $15.3 \%$ of all non-fatal casualties ${ }^{20}$. Another factual error concerns the assertion that electric blankets and space heaters are "a common cause" of fires. Again a check of the same set of fire statistics reveals that space heaters were the source of ignition of just $3.6 \%$ of all ADFs while electric blankets were the source of ignition in a mere $0.3 \%$ of $\mathrm{ADFs}^{20}$; figures which could hardly be considered to fit the definition of a common cause.

A study by Lehna et al. outlined the aim of creating and validating a "cartographic risk model" to identify geographical areas in which there is a greater risk of fires occurring (although the types of fires are not explicitly stated, the risk factors the authors identify suggest a focus on dwelling fires $)^{79}$. Unfortunately, despite the paper's stated aims, the attempt to do this is undermined 
by the fact that the authors use terminology relating to risk of fire occurrence and risk of fire injury interchangeably, treating them as one and the same. This means that throughout that paper there are numerous references to risk and risk factors without an identification of which type of risk is being referred to: fire occurrence or fire injury. Unfortunately, this represents a failure to identify and understand that the risk of fire occurrence and fire injury are in fact two different types of risk. However, an increasing body of work has begun to question this simplistic, and erroneous, assumption $^{8,71,75,80}$. One of the earliest pieces of work to highlight this difference was the study carried out using data from 150 fatalities from 109 fatal residential fires between 1990 and 1995 in the State of Victoria in Australia ${ }^{54}$. The study considered the characteristics and behaviour of victims and survivors and identified the important distinction between the risk of a fire occurring and the ability to respond effectively to a fire once it has started.

Of a slightly different but nonetheless related focus is the work by Xiong et al. which, drawing from Australian coroners' fire fatality reports and non-fatal fire incident data, sought to identify and compare the difference in risk factors associated with fatal compared to non-fatal $\mathrm{ADFs}^{62}$. This work identified the main risk factors associated with fatal fires as psychotropic and sedative drug intake, discarded cigarettes, living alone, being aged over 70 and being asleep. For non-fatal ADFs the associated risk factors were cooking fires, electrical fires, the kitchen being the room of fire origin, a stove (oven) being involved in the fire starting, and the fire being in a one- or two-family dwelling ${ }^{62}$. Although this work identifies that risk factors for fatal fires differ from nonfatal fires and offers a useful overview of the differences between these two risk profiles, the work remains constrained by its inability to tease apart the nature of each of the factors, i.e. whether they are related to ignition or risks posed once a fire started. Moreover, it adopts a fairly deterministic standpoint, in that risk factors related to non-fatal outcomes are the circumstances around the fire starting and the building type; clearly these have a role to play, but the work's emphasis on these alone fails to recognise the importance of individuals' actions and behaviours. Although the authors 
touch on this in their conclusion regarding fatal fires, namely the already well-established fact that there is an association with cognitive or physical impairment in fatal fires, human agency as applied to non-fatal fires is not really put into focus. Instead the authors limit their scope to view the determinants of non-fatal fires as the consequence of environmental-based risk factors. The closest consideration of human behaviour is a brief section that discusses "reported or observed behaviour before the fire"; yet the conclusion of this section is that "hosts who displayed unusual behaviours were at higher risk of dying in accidental residential fires than those who behaved normally before the fire" (Xiong et al., 2015 $5^{62}$, p43). As the authors state the time frame "before the fire" could be days or months, and they offer no identification or definition of what constitutes either "unusual" or "normal" behaviour before a fire. Nor is any context or background given as to how such "unusual" or "normal" behaviour before a fire may affect the risk of dying during a fire. Consequently, it is difficult to make inferences from this work about the role of human behaviour in non-fatal fires, an outcome that further underscores the need for a robust body of evidence of human behaviour during ADFs.

Of note is the qualitative work on fire risk that has been undertaken by the University of Salford in conjunction with Greater Manchester FRS ${ }^{71,81}$. Using in-depth interviews with those who have experienced a fire in their home, this work offers a different approach in that, rather than attempting to offer a quantified form of risk analysis, it seeks to understand how the experience of an ADF influences that individual's perceptions of fire occurrence risk, the manner in which they reflect on the fire (through the type of terminology and choice of language used) and their opinion of the likelihood of experiencing another fire ${ }^{71,81}$. In general terms, findings from the work have shown that those who have experienced an ADF tend to focus on future fire occurrence risks only in relation to the type of fire they experienced, not generic fire occurrence risks ${ }^{81}$. Through its adoption of a deliberately non-standard perspective, this work offers a useful and much-needed contribution to the literature on fire risk more generally. 
At the other end of the methodological scale a study carried out in Sweden has specifically sought to identify and quantify what differences may exist in risk factors related to having a fire in the home and dying in such a fire ${ }^{75}$. Based upon a sample of over 13,000 respondents, 405 of which had experienced a fire, the study concluded that, differentiated for respondent characteristics and household characteristics, the risk of a dwelling fire occurring was higher among younger compared to older age groups (defined as 18 to 30 years compared to those over 61 years), increased among those born outside of the Nordic countries (it is argued that this is due to higher smoking rates among immigrants and cooking practices that are more likely to result in burn injuries among children in such families) and increased among those with "higher" educational levels (as defined by the International Standard Classification of Education). Although unable to account for the reason why dwelling fires are more common among those with a higher educational level - the study's authors somewhat unconvincingly speculate that it may be related to such groups having higher incomes and therefore more "technical" (presumably electrical) equipment - this is nonetheless an important, and surprising, finding, particularly as low educational level has been identified as a risk factor related to fire fatalities ${ }^{57,61,63}$. Regarding household characteristics, an increased fire occurrence risk was observed with households with five or more occupants and those with children, particularly aged 6 to 12 years; something that is believed by the authors to be accounted for by this age group being the most likely to experiment with matches and lighters. In their summary the authors make an important point that, based upon these results, the risk of dying in a house fire is not due to a higher frequency of fires.

What becomes clear is that the risk of a fire occurring and the risk of becoming a casualty due to a fire must be distinguished. Moreover, those who die and those who survive ADFs (either with or without injury) must be considered as at least two different groups. Consequently it is inaccurate to regard ADF injuries simply as near miss fatalities as this viewpoint rests on an assumption that all occupants are passive and moving on a pre-determined course that would end in death if not for the 
intervention of others or some stroke of good fortune. On the contrary, recent studies have begun to show that during an ADF occupants actively move around the property and undertake a number of tasks during the fire $\mathrm{f}^{4,51,52}$. There is also the possibility that through their own actions during the fire, occupants could avoid becoming a casualty.

\section{Conclusions}

It is apparent from the discussion of the existing literature that, since the initial work carried out on human behaviour in fire by Wood and Bryan and the direct comparisons of occupancy and building types undertaken by Canter et al., compared to the abundant and rich body of literature on human behaviour in PCI spaces, there has been a very limited focus upon understanding how people behave during a fire in dwellings, particularly single family/occupant dwellings. It is clear that the greatly different environmental, physical and social circumstances that are present in dwelling fires compared to fires in PCI spaces means that knowledge relating to human behaviour in the latter cannot be assumed to be applicable to the former. This gap in the knowledge of behaviour in dwelling fires has only been partially filled to date as the work that has dealt with domestic environments has been dominated by a focus upon identifying the occupant and environmental risk factors related to dwelling fire fatalities. From this literature a consensus has emerged about those groups who are at increased risk of dying with the risk factors having been identified in studies undertaken in the UK, North America, Japan, Australia and New Zealand. Moreover, there are also identified similarities in the causes of dwelling fires that result in fatalities. Recently, there has begun to be a greater recognition of the distinction between the risk of having a fire, the risk of being injured, and risk of dying in a fire. The realisation that those who are injured in fires are not near miss fatalities but are in fact a group that is different from those who die in fires has led to some initial attempts to tease out and identify the determinants related to these two very different risks. Understanding why people are injured in fires is important and more work needs to be done in this area; something that underscores the need for a contemporary and comprehensive understanding of 
human behaviour in fires in the home. 


\section{References}

1. Bryan JL (1999) 'Human Behaviour in Fire: The Development and Maturity of a Scholarly Study Area', Fire and Materials, Vol.23, No. 6, November-December 1999, pp 249-253

2. Kobes M, Helsloot I, de Vries B and Post Jos G (2010) 'Building Safety and Human Behaviour in Fire: A Literature Review', Fire Safety Journal Vol 45, Issue 1, January 2010

3. Babrauskas Vytenis (2013) 'Some neglected areas in fire safety engineering', Fire Science and Technology, Vol.32, No. 1, pp35-48

4. Thompson OF and Wales D (2015) 'A Qualitative Study of Experiences, Actions, and Motivations During Accidental Dwelling Fires'. Fire and Materials. Vol 39, Issue 4, pp453-465, June 2015

5. Wood PG (1972), 'The Behaviour of People in Fires', Fire Research Note 953, Building Research Establishment, Borehamwood

6. Bryan JL (1977), 'Smoke as a Determinant of Human Behaviour in Fire Situations', University of Maryland, College Park

7. Canter D (Ed) (1990) Fires and Human Behaviour, John Wiley and Sons, New York

8. Brennan P and Thomas I (2001) 'Victims of Fire? Predicting outcomes in Residential Fires' in Human Behaviour in Fire Proceedings of the $2^{\text {nd }}$ International Symposium, pp241- 251, Cambridge, Boston (MA), USA

9. Sekizawa A (2005), 'Reducing Fatalities in Residential Occupancies', Fire Protection Engineering, Number 25, pp20-26

10. Flynn JD (2010), Characteristics of Home Fire Victims, Fire Analysis and Research Division, NFPA

11. Graesser H, Ball M and Bruck D (2009) 'Risk factors for residential fire fatality across the lifespan: comparing coronial data for children, adults and elders'. $4^{\text {th }}$ International Symposium on Human Behaviour in Fire, Conference Proceedings, Interscience Communications, London

12. Proulx G (1998) 'The Impact of Voice Communication Messages During A Residential Highrise Fire'. Human Behaviour in Fire Proceedings of the First International Symposium, Fire SERT Centre, University of Ulster, pp265-274

13. Sekizawa A, Ebihara M, Notake H, Kubota K, Nakano M,Ohmiya Y, and Kaneko H (1999), 'Occupants' Behaviour in Response to the High-Rise Apartments Fire in Hiroshima City', Fire and Materials, 23, pp297-303

14. Kobes M, Post J, Helsloot I and de Vries B (2008) 'Fire risk of high-rise buildings based on human behaviour in fires', Conference Proceedings FSHB 2008. First International Conference on Fire Safety of High-rise Buildings. Bucharest, Romania, May 07-09 2008. Available online at: http://www.nifv.nl/upload/129028_668_1212155436343-20080507_FSHB_M_Kobes_Fire_risk_of_highrise buildings based on human behavior_in_fires.pdf Accessed on 09/01/2015

15. Barber DJ (2009) 'Strategies for occupant response to fire in high-rise residential buildings', B Lee Scholarship Report, Fire Protection Association, Australia

16. Mansi P (2013) 'Outcomes and lessons learned from the major investigation of the Lakanal fire in London UK'. Interflam 2013: 13th International Fire Science \& Engineering Conference. London, Interscience Communications, pp. $1535-1546$

17. Bryan JL (2002) 'A selected historical review of human behaviour in fire', Journal of Fire Protection Engineering 16 , pp 4-10

18. Wales D and Thompson OF (2013) Human behaviour in fire: should the fire service stop telling and start listening? International Journal of Emergency Services, Vol.2, No.2, Emerald, London

19. Boyce K (Ed) (2015) Human behaviour in fire papers. A compendium of research papers. Interscience Communications Ltd, London (on CD)

20. Department for Communities and Local Government (2015) Fire Statistics Great Britain: 2013 to 2014 . Available online at: https://www.gov.uk/government/statistics/fire-statistics-great-britain-2013-to-2014 Accessed on 07/04/2016

21. Home Office (2016). Fire statistics data tables. Available online at: https://www.gov.uk/government/statistical-datasets/fire-statistics-data-tables Accessed on 07/12/2016

22. Scottish Fire and Rescue Service (2016). Fire and Rescue Incident Statistics Scotland 2015-16. Available online at: http://www.firescotland.gov.uk/media/1009443/fire_and_rescue_statistics_scotland_2015_16.pdf Accessed on 07/12/2016

23. Welsh Government (2016) Fire statistics Wales, 2015-16.Available online at: http://gov.wales/docs/statistics/2016/160727-fire-statistics-2015-16-en.pdf Accessed on 07/12/2016

24. Department for Communities and Local Government (2016) Dwelling Stock Estimates: 2015, England. Available online at: https://www.gov.uk/government/uploads/system/uploads/attachment_data/file/519475/Dwelling_Stock_Estimates_2 015 England.pdf Accessed on 07/12/2016 
25. Jefferies J (2005) Focus on People and Migration, Chapter 1. Office for National Statistics. Available online at: http://www.ons.gov.uk/ons/rel/fertility-analysis/focus-on-people-and-migration/december-2005/index.html Accessed on 28/04/2015

26. Office for National Statistics (2018). Population estimates. Available online at: https://www.ons.gov.uk/peoplepopulationandcommunity/populationandmigration/populationestimates Accessed on 25/02/2018

27. Department for Communities and Local Government (2010) Fire Statistics: UK 2008. Available online at: https://www.gov.uk/government/statistics/fire-statistics-uk-2008 Accessed on 04/06/2015

28. Department for Communities and Local Government (2011) 'The economic cost of fire: estimates for 2008', 'Fire research report' 3/2011, February 2011, London

29. Bennett, R (2002) 'Human behaviour: Ok - so this is what the experts say but how do people really behave?', Fire Safety, Technology \& Management: incorporating the Journal of the Fire Service College, Vol. 7, No. 2, Summer 2002, pp35-45

30. Lawson G, Sharples S, Clarke D, Cobb S (2009) 'The Use of Experts for Predicting Human Behaviour in Fires' $4^{\text {th }}$ international Symposium on Human Behaviour in Fire, Conference Proceedings, Interscience Communications, London, pp493-500

31. Quarantelli EL (1954) 'The nature and conditions of panic', American Journal of Sociology, 60, pp265-275

32. Canter D (1996) 'An Overview of Behaviour in Fires' in Psychology in Action, Dartmouth Publishing Company, Hampshire, UK

33. Proulx G (2001) 'Occupant Behaviour and Evacuation'. National Research Council Canada, NRCC-44983. Available online at: http://www.cfaa.ca/Files/flash/CODES/LIFE\%20SAFETY\%20SYSTEM\%20RESEARCH/Occupant\%20behaviour $\% 20$ and\%20evacuation\%20nrcc44983.pdf Accessed on 13/10/2016

34. Proulx G (2002) 'Cool under fire'. National Research Council Canada, NRCC-45404. Available online at: https://nparc.nrc-cnrc.gc.ca/eng/view/accepted/?id=64aac2e8-6108-4960-9d29-de91025d5d06 Accessed on $15 / 10 / 2016$

35. Proulx G (2003) 'Playing with fire: understanding human behaviour in burning buildings', National Research Council Canada, NRCC-46619 Available online at: http://citeseerx.ist.psu.edu/viewdoc/download;jsessionid=DDDB087F86941338A3D40D42BCDA4AE3?doi=10.1.1. $10.2387 \&$ rep $=$ rep $1 \&$ type $=$ pdf Accessed on 15/10/2016

36. Galea ER (2009), 'Evacuation Response Phase Behaviour', CMS Press, University of Greenwich, report number 09/IM/147, ISBN 978190452162 4, October 2009

37. Schmidt S and Galea ER (Eds) (2013) Behaviour - Security - Culture. Human behaviour in emergencies and disasters: A cross-cultural investigation. Padst, Lengerich, ISBN 978-3-89967-867-3

38. Day R, Hulse LM, Galea ER (2013) 'Response Phase Behaviours and Response Time Predictors of the 9/11 World Trade Center Evacuation', Fire Technology, Vol. 49, Issue 3, pp657-678

39. Galea ER, Hulse L, Day R, Siddiqui A and Sharp G (2012) 'The UK WTC 9/11 evacuation study: An overview of findings derived from first-hand interview data and computer modelling'. Fire and Materials. Vol. 36, No. 5-6, pp $501-521$

40. Shields TJ and Proulx G (2000) 'The science of human behaviour: past research endeavours, current developments and fashioning a research agenda', Proceedings of the Sixth international Symposium on Fire Safety Science, IAFSS, pp95-114

41. Shields TJ, Boyce KE and Silcock GWH (1999) 'Towards the characterization of large retail stores'. Fire and Materials, Vol. 23, Issue 6, pp325-331, November/December 1999

42. Dubner S (2011) Freakonomics Radio. Death by Fire? Probably Not. Available online at: http://freakonomics.com/2011/03/24/freakonomics-radio-death-by-fire-probably-not/ Accessed on 04/06/2016

43. Babrauskas V, Fleming JM and Russell D (2010) 'RSET/ASET, a flawed concept for fire safety assessment', Fire and Materials. Vol 34, pp341-355

44. Proulx G and Fahy RF (1997) 'Time Delay to Start Evacuation: Review of Five Case Studies', in Hasemi Y (Ed) Proceedings of the $5^{\text {th }}$ International Symposium on Fire Safety Science, pp783-794

45. Proulx G, Pineau J, Latour JC, and Stewart L (1995) Study of the Occupants' Behaviour During the 2 Forest Laneway Fire in North York, Ontario, January 6, 1995. National Research Council Canada, Internal Report \#705

46. Nilsson D and Johansson A (2009) 'Social influence during the initial phase of a fire evacuation - Analysis of evacuation experiments in a cinema theatre'. Fire Safety Journal, Vol. 44, Issue 1, January 2009 pp71-79. Available online at: http://www.sciencedirect.com/science/article/pii/S0379711208000362 Accessed on 19/03/2016

47. Galea ER (2009), 'Exploring the Impact of Culture and Staff Intervention on Evacuation Response Phase Behaviour', CMS Press, University of Greenwich, report number 09/IM/148, ISBN 978190452163 1, November 2009 
48. Galea ER, Deere SJ, Sharp G, Filippidis L, and Hulse L (2010) Investigating the impact of culture on evacuation behaviour. Proceedings of the $12^{\text {th }}$ International Fire Science and Engineering Conference, Interflam 2010, pp879892

49. Bryan J L (2002) 'Behavioral Response to Fire and Smoke', in The SFPE Handbook of Fire Protection Engineering $3^{\text {rd }} E d$. DiNenno PJ, Drysdale D, Beyler, CL, Walton WD, Custer, RLP, Hall JR and Watts JM (Eds) Quincy MA: National Fire Protection Association, pp315-341

50. Office of the Deputy Prime Minister (2006). Fires in the Home: findings from the 2004/05 Survey of English Housing, 2006. Available online at: http://www.communities.gov.uk/documents/fire/pdf/143501.pdf Accessed on $26 / 06 / 2016$

51. Thompson OF, Hulse L, Wales, D and Galea ER (2013) “"Get Out, Stay Out” versus Occupier Independence: The Results of an 18 Month Study of Human Behaviour in Accidental Dwelling Fires in Kent', Proceedings of the $13^{\text {th }}$ International Interflam Conference 2013, Interscience Communications, London, pp943-954

52. Wales D and Thompson OF (2012) 'Behaviours, Motivations and Timescales: Towards the Development of a Comprehensive Database of Human Behaviour in Dwelling Fires', Proceedings of the $5^{\text {th }}$ International Symposium on Human Behaviour in Fire, Interscience Communications, London, pp218-229

53. Proulx, G (2009) 'Evacuation from a Single Family House', $4^{\text {th }}$ International Symposium on Human Behaviour in Fire, Conference Proceedings, Interscience Communications, London

54. Brennan P (1998) 'Victims and Survivors in Fatal Residential Building Fires', in Shields J (Ed) Human Behaviour in Fire Proceedings of the $1^{\text {st }}$ International Symposium, Belfast, UK pp157-166

55. Greene MA and Andres C (2009). 2004-2005 National Sample Survey of Unreported Residential Fires. US Consumer Product Safety Commission, 2009. Available from: http://www.cpsc.gov/library/foia/foia09/os/UnreportedResidentialFires.pdf Accessed on 17/07/2014

56. Brennan P (1997) 'Timing Human Response in Real Fires'. Fire Safety Science - Proceedings of the Fifth International Symposium, pp807-818. Available online at: http://www.iafss.org/publications/fss/5/807/view Accessed on 04/09/2015

57. Lewis C and Lear A (2003) 'A matter of life and death', pp47-49, FEJ \& FP, July 2003

58. U.S. Fire Administration (2015) U.S. fire statistics. Available online at: http://www.usfa.fema.gov/data/statistics/ Accessed on 07/04/2016

59. Runyan CW, Bangdiwala SI, Linzer MA, Sacks JJ and Butts J (1992) 'Risk Factors for Fatal Residential Fires'. New England Journal of Medicine 327(12), pp859-863

60. Sekizawa A (2015) 'Challenges in Fire Safety in a Society Facing a Rapidly Aging Population'. Fire Protection Engineering. $1^{\text {st }}$ Quarter, 2015, pp31-38

61. New Zealand Fire Service Commission (2005), Human Behaviour Contributing to Unintentional Residential Fire Deaths, New Zealand Fire Service Commission Research Report Number 47, Heimdall Consulting Ltd

62. Xiong L, Bruck D and Ball M (2015) "Comparative investigation of 'survival' and fatality factors in accidental residential fires”, Fire Safety Journal, 73, pp37-47

63. Jennings CR (2013) 'Social and economic characteristics as determinants of residential fire risk in urban neighbourhoods: A review of the literature'. Fire Safety Journal. Vol. 62, Part A, pp13-19

64. Shai D and Lupinacci PL (2003) 'Fire Fatalities Among Children: An Analysis Across Philadelphia's Census Tracts', Public Health Reports, March-April 2003, Vol 118, pp115-126

65. Harpur AP, Boyce KE and McConnell NC. (2013) An Investigation into the Circumstances Surrounding Fatal Dwelling Fires Involving the Elderly During 1999-2009. Interflam 2013: 13th International Fire Science \& Engineering Conference. London, Interscience Communications, pp931-942

66. Elder AT, Squires T and Busuttil A (1996) 'Fire Fatalities in Elderly People'. Age and Ageing. Vol. 25, 1996, pp214-216

67. DiGuiseppi C, Edwards P, Godward C, Roberts I \& Wade A (2000) 'Urban residential fire and flame injuries: a population based study', Injury Prevention, 6(4) pp250-254

68. Lionelli G.T., Pickus E.J., Beckum O.K., DeCoursey R.L. and Korentager R.A. (2005) "A three decade analysis of factors affecting burn mortality in the elderly" Burns Vol. 31, Issue 8, pp958-963. Available online at: http://www.burnsjournal.com/article/S0305-4179(05)00183-X/abstract Accessed on 08/04/2015

69. Keck M., Lumenta D.B., Andel H., Kamolz L.P. and Frey M., (2009) "Burn treatment in the elderly". Burns. Vol. 35, Issue 8, pp1071-1079 Available online at: http://www.burnsjournal.com/article/S0305-4179(09)00088-6/abstract Accessed on 08/04/2015

70. Bruck D, and Thomas IR (2012) 'Community-based research on the effectiveness of the home smoke alarm in waking up children', Fire and Materials, August-October 2012, Vol 36, Issue 5-6, pp339-348

71. Clark A, Smith J and Conroy C (2014) 'Domestic fire risk: a narrative review of social science literature and implications for further research'. Journal of Risk Research DOI: 10.1080/13669877.2014.913660

72. Harpur AP, Boyce KE and McConnell NC. (2012) An Investigation into Fatal Dwelling Fires Involving Children Aged Five Years and Under. Human Behaviour in Fire, Proceedings of the Fifth International Symposium, 2012, pp230-238 
73. Warda L, Tenenbein M, Moffatt MEK (1999) 'House fire prevention update. Part 1. A review of risk factors for fatal and non-fatal house fire injury'. Injury Prevention Vol 5, issue 2, pp145-150

74. Eisenberg EF (2005) 'Fire Deaths in the United States: How Best to Keep Reducing Them', Fire Protection Engineering, Number 25, Winter 2005, pp10-19

75. Nilson F, Bonander C, and Jonsson A (2015) Differences in Determinants Amongst Individuals Reporting Residential Fires in Sweden: Results from a Cross-Sectional Study. Fire Technology, Vol. 51, Issue 3, pp615-626

76. Greenstreet Berman (2012) Review of DFRS Dwelling Fire Safety Strategy, Dorset Fire and Rescue Service

77. Breslin D, Burkitt M and Romano D (2015) Modelling Connectivity and Co-evolution: The 'Premonition' Study of Domestic Fire Risk Behaviours. Presented at 'How do you talk to people if they don't exist?', An information sharing event for the fire and rescue service, ESRC Festival of Social Science, $9^{\text {th }}$ November 2015, London Fire Brigade HQ. Available online at http://www.cfoa.org.uk/20194 Accessed on 06/06/2016

78. Barnett M (2008) Risk Factors and Incidence of Residential Fire Experiences Reported Retrospectively. PhD thesis, Centre for Environmental Safety and Risk Engineering, School of Psychology, Victoria University

79. Lehna C, Speller A, Hanchette C, Fahey E, Coty M (2015) 'Development of a Fire Risk Model to Identify Areas of Increased Potential for Fire Occurrences' Journal of Burn Care \& Research, 37(1), pp12-19

80. Greene MA (2012) 'Comparison of the characteristics of fire and non-fire households in the 2004-2005 survey of fire department attended and unattended fires'. Injury Prevention, 18 (3), pp170-175

81. Clark A and Smith J (2015) 'Experiencing a domestic fire: an overview of key findings from a post incident research programme'. Safer Communities, Vol. 14, No. 2, pp95-103 